\title{
Fuzzy Evaluation Model of Integrated Security for Highway Subgrade after Earthquake
}

\author{
C. LI,B.Y. SHEN \\ National Engineering \& Research Center for Highways in Mountain Area, Chongqing, P.R. \\ China \\ College of Water Resources and Civil Engineering, China Agricultural University, Beijing, P.R. \\ China
}

KEYWORD: Subgrade of Highway; Evaluation of Integrated Security Situation; Analytic Hierarchy Process; Fuzzy Evaluation Model

ABSTRACT: Five indexes have been selected to figure characteristics of subgrade: damage condition, structural characteristics, such as height, slope ratio, etc., aftershock strength, features of terrain and physiognomy, rainfall intensity. Fuzzy AHP Comprehensive Evaluation Method, FACEM, has been introduced to determine weight of above-mentioned indexes and assess the general security degree of subgrade after earthquake. Furthermore, illustrative example has been given with damaged subgrade of national highway G212 after 5.12 Wenchuan earthquake. The research has shown that judgment results obtained by FACEM does almost match with advices given by professional experts after investigation. But there has been more persuasion and conviction with the quantitative approach to deal with uncertain information generated in process of evaluation for FACEM.

\section{INTRODUCTION}

In the Paper, we employ Fuzzy AHP Comprehensive Evaluation Method (FACEM) to evaluate integral subgrade safety after earthquakes. Fuzzy evaluation is to introduce fuzzy concepts in the process of evaluation and deals with some issues of subgrade seismic damage evaluation by using fuzzy mathematics, to reflect subgrade damage conditions after earthquakes and safety uncertainty. Analytic Hierarchy Process (AHP) compares various factors in pairs in the evaluation system, calculates the weight of each factor and makes decisions on the evaluated objects as per comprehensive weights. Combining the two methods in the comprehensive evaluation of the evaluated objects is the FACEM. [1-6]

\section{MATHEMATICAL MODEL OF FUZZY COMPREHENSIVE EVALUATION}

We assume that discourse domain $U=\left\{u_{1}, u_{2}, \ldots, u_{n}\right\}$ are $n$ factors relevant to the evaluated factors, the discourse domain $U$ is called index set or factor set. $V=\left\{v_{1}, v_{2}, \ldots, v_{m}\right\}$ is comment set, while the fuzzy relation between domain discourse of evaluation factor set and domain discourse of comment set can be indicated by matrix $R$ :

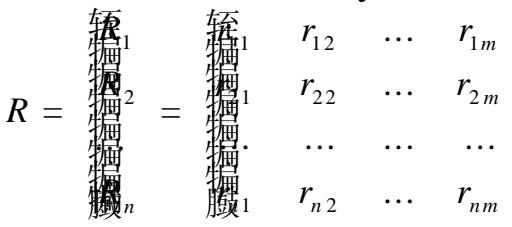

Where $r_{i j}=\mu\left(u_{i}, v_{j}\right)\left(0 \leq r_{i j} \leq 1\right)$ expresses membership degree of factor $u_{i}$ evaluated to $v_{j}$; in the row $i$ of matrix $R, R_{i}=\left\{r_{i 1}, r_{i 2}, \ldots, r_{i m}\right\}$ is the ith single-factor evaluation of evaluation factor $u_{i}$, as well as the fuzzy subset of $V$.

Actually, different factors play different roles in each evaluation grade, which means factor weights should be considered.

We assume that $w_{1}, w_{2}, \ldots, w_{n}$ are respectively the weights to evaluate $u_{1}, u_{2}, \ldots, u_{n}$ and satisfy $w_{1}+w_{2}+\ldots+w_{n}=1$. If $W=\left\{w_{1}, w_{2}, \ldots, w_{n}\right\}, W$ is the fuzzy sets of factor weights (namely weight vector). According to fuzzy comprehensive evaluation principle: 
$B=W \cdot R=\left(w_{1}, \ldots, w_{n}\right) \cdot\left[\begin{array}{cccc}r_{11} & r_{12} & \ldots & r_{1 m} \\ r_{21} & r_{22} & \ldots & r_{2 m} \\ \ldots & \ldots & \ldots & \ldots \\ r_{n 1} & r_{n 2} & \ldots & r_{n m}\end{array}\right]=\left(b_{1}, \ldots, b_{m}\right)$

We normalize results of $B$ and take $b^{*}=\max \left\{b_{1}, \ldots, b_{m}\right\}$, the corresponding grade is the evaluation grade, then we obtain the comprehensive evaluation result $V$.

\section{DETERMINATION OF MEMBERSHIP DEGREE}

As for application, it needs to establish membership function of fuzzy sets firstly. On the basis of consulting reference materials, we, according to the practical conditions of integral safety evaluation of highway subgrade after earthquakes and to the features of each index, planned to determine each membership function as triangular fuzzy membership function, of which the mathematical expression is shown as equation (3), where $a_{1}$ and $a_{3}$ are end-points of sections and $a_{2}$ is the midpoint of sections.

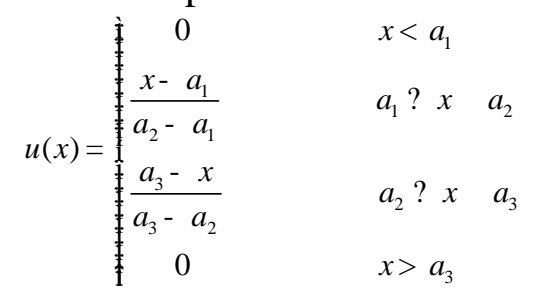

\section{WEIGHT DETERMINATION}

AHP is a kind of analytical tools for decision making which solves multi-purpose complicated issues by a combination of qualitative and quantitative methods, proposed by a U.S. operational research expert, Professor A. L. Saaty from the University of Pittsburgh in 1970s [7]. Principal steps determining evaluation index weight by AHP are as follows:

Determine influencing factors and establish a hierarchical structural model

First of all, we dissemble a complicated issue into several indexes and group these indexes to form different hierarchies to make it systematic. In practical application, we generally classify hierarchical structure into three levels. The first level is the goal, usually with only one index, indicating the aim to be finally achieved. The second is principle, indicating the standard for achieving the anticipated aim. And the third is index, indicating specific factors or indexes influencing the anticipated aim.

\section{Establish a comparison and determination matrix}

After establishing a hierarchical structure, the membership relationship between factors on the upper and lower levels has been determined. Determination matrix is the basic information of AHP. It judges relative importance of each factor at each level and the judgments are indicated by digits in matrix, which is determination matrix. We compare the importance of factors in pairs of this level regarding a factor in the last level as the evaluation principle to determine matrix factors. We establish a determination matrix for each level except for the highest level and the number of determination matrix of each level equals to the number of the factors of the last level. It is hard to obtain relative importance among all factors of a level by rigorous statistical methods. Hence, in AHP, we determine it by comparison in pairs. We assume the evaluation index is $A$, evaluation index factor set $F=\left\{f_{1}, f_{2}, \ldots, f_{n}\right\}$ and the structural determination matrix $P(A-F)$ is:

$$
P=\left[\begin{array}{cccc}
f_{11} & f_{12} & \cdots & f_{1 n} \\
f_{21} & f_{22} & \cdots & f_{2 n} \\
\cdots & \cdots & \cdots & \cdots \\
f_{n 1} & f_{n 2} & \cdots & f_{n n}
\end{array}\right]
$$


Where, $f_{i j}$ indicates relative importance of factors. $(i=1,2, \ldots, n ; j=1,2, \ldots, n)$. To quantitatively describe relative importance of any two factors as per a principle, we employ 1 9 scaling procedure for scale of numbers in the Paper. See Table 1 for the specific values.

Table 1. 1 9 Scaling Procedure and Their Significance.

\begin{tabular}{|c|c|c|}
\hline Scale & Definition & Description \\
\hline 1 & $\begin{array}{l}\text { Equally } \\
\text { important }\end{array}$ & $\begin{array}{l}\text { In comparison, two factors } \\
\text { are equally important }\end{array}$ \\
\hline 3 & $\begin{array}{l}\text { Slightly } \\
\text { more } \\
\text { important }\end{array}$ & $\begin{array}{l}\text { In comparison, one factor is } \\
\text { slightly more important than } \\
\text { the other }\end{array}$ \\
\hline 5 & $\begin{array}{l}\text { Distinctly } \\
\text { more } \\
\text { important }\end{array}$ & $\begin{array}{l}\text { In comparison, one factor is } \\
\text { distinctly more important } \\
\text { than the other }\end{array}$ \\
\hline 7 & $\begin{array}{l}\text { Much more } \\
\text { important }\end{array}$ & $\begin{array}{l}\text { In comparison, one factor is } \\
\text { much more important than } \\
\text { the other }\end{array}$ \\
\hline 9 & $\begin{array}{c}\text { Extremely } \\
\text { more } \\
\text { important }\end{array}$ & $\begin{array}{l}\text { In comparison, one factor is } \\
\text { extremely more important } \\
\text { than the other }\end{array}$ \\
\hline $\begin{array}{l}1 / 3 \\
1 / 5 \\
1 / 7 \\
1 / 9 \\
\end{array}$ & $\begin{array}{l}\text { Converse } \\
\text { comparison }\end{array}$ & $\begin{array}{l}\text { If we obtain } r_{i j} \text { by comparing } \\
\text { factors } c_{i} \text { with } c_{j} \text {, then we get } \\
\text { the determination } r_{j i}=1 / r_{i j} \text { by } \\
\text { comparing } c_{j} \text { with } c_{i}\end{array}$ \\
\hline
\end{tabular}

Relative importance calculation

The text should fit exactly into the type area of $187 \times 272 \mathrm{~mm}(7.36 " \times 10.71 ")$. For correct settings of margins in the Page Setup dialog box (File menu) see Table 1.

By using linear algebra, we acquire the feature vector corresponding to the maximum eigenvalue of determination matrix and then normalize the feature vector to obtain weight distribution. The feature vector corresponding to the maximum eigenvalue of determination matrix can be calculated by squareroot method.

(1) Calculate product $W_{i}$ of the factors at every row of the determination matrix $W_{i}=\prod_{j=1}^{n} f_{i j}(i=1,2, \ldots, n)$

(2) Calculate $n^{\text {th }}$ root of $W_{i}$ $\overline{W_{i}}=\sqrt[n]{W_{i}}$

(3) Normalize vector $\bar{W}=\left(\overline{W_{1}}, \overline{W_{2}}, \ldots, \overline{W_{n}}\right)$

$$
w_{i}=\frac{\overline{W_{i}}}{{\stackrel{\mathrm{a}}{i}{ }^{n} \overline{W_{i}}}_{\overline{1}}}
$$

then $W=\left\{w_{1}, w_{2}, \ldots, w_{n}\right\}$ is the feature vector to be acquired.

(4) Calculate the maximum eigenvalue of the matrix

$\lambda_{\max }=\frac{1}{n} \sum_{i=1}^{n} \frac{(P W)_{i}}{w_{i}}$

Where $(P W)_{i}$ indicates the $i^{\text {th }}$ factor of vector $P W$. 
$P W=\left[\begin{array}{c}(P W)_{1} \\ (P W)_{2} \\ \ldots \\ (P W)_{m}\end{array}\right]=\left[\begin{array}{cccc}f_{11} & f_{12} & \ldots & f_{1 n} \\ f_{21} & f_{22} & \ldots & f_{2 n} \\ \ldots & \ldots & \ldots & \ldots \\ f_{n 1} & f_{n 2} & \ldots & f_{n n}\end{array}\right] \cdot\left[\begin{array}{c}w_{1} \\ w_{2} \\ \ldots \\ w_{n}\end{array}\right]$

Consistency test

Relative weight calculated based on determination matrix is to be conducted with consistency test of determination matrix. The test equation is:

$C R=C I / R I$

Where $C I=\frac{1}{n-1}\left(\lambda_{\max }-n\right), R I$ are random consistency indexes of determination matrix, shown as follows:

Table 2. Random Consistency Indicators.

\begin{tabular}{cccccccc}
\hline $\boldsymbol{n}$ & $\mathbf{1}$ & $\mathbf{2}$ & $\mathbf{3}$ & $\mathbf{4}$ & $\mathbf{5}$ & $\mathbf{6}$ & $\mathbf{7}$ \\
\hline$R I$ & 0 & 0 & 0.58 & 0.9 & 1.12 & 1.24 & 1.32 \\
\hline \hline $\boldsymbol{n}$ & $\mathbf{8}$ & $\mathbf{9}$ & $\mathbf{1 0}$ & $\mathbf{1 1}$ & $\mathbf{1 2}$ & $\mathbf{1 3}$ & $\mathbf{1 4}$ \\
\hline$R I$ & 1.41 & 1.45 & 1.49 & 1.51 & 1.54 & 1.56 & 1.58 \\
\hline
\end{tabular}

When $C R<0.10$, we regard the consistency of determination matrix as acceptable and the feature vector corresponding to $\lambda_{\max }$ can be the weight vector for sorting. Otherwise, the determination matrix should be properly corrected until it is satisfying.

Calculation of integral importance

Integral importance is calculated to acquire the importance of factors at each level to the whole system.

Due to subgrade damage conditions, environmental factors and complexity of rock-soil mass itself, the influence of many factors to its performance and their acting mechanism are not completely clear when evaluating subgrade safety after earthquakes. Since the system is featured as "fuzzy", it is appropriate to employ FACEM for analysis.

See Table 3 for grading rule of each factor based on the 5 safety grades mentioned above. Its factor set and evaluation set are established as follows:

(1) Determine factor set

$$
U=\left\{U_{1}, U_{2}, U_{3}, U_{4}, U_{5}, U_{6}\right\}
$$

Where, $U_{1}$ is subgrade damage condition, $U_{2}$ topographical and geomorphologic features, $U_{3}$ aftershock magnitude, $U_{4}$ subgrade height, $U_{5}$ slope ratio and $U_{6}$ rainfall intensity.

(2) Establish evaluation set

$$
V=\left\{V_{1}, V_{2}, V_{3}, V_{4}, V_{5}\right\}
$$

Where, $V_{1}$ is safe, $V_{2}$ basically safe, $V_{3}$ less safe, $V_{4}$ unsafe and $V_{5}$ extremely unsafe.

Moreover, if the units of each evaluation index are different, it needs to conduct dimensionless treatment for index data by extreme deviation to eliminate the influence of dimension and to express the data in a unified manner, as Table 3 shows. The method of dimensionless treatment is as follows:

For the factors the bigger the better, we employ:

$$
x_{i j}^{\prime}=\frac{x_{i j}-x_{i \min }}{x_{i \max }-x_{i \min }}
$$

For the factors the smaller the better, we employ:

$$
x_{i j}^{\prime}=\frac{x_{i \max }-x_{i j}}{x_{i \max }-x_{i \min }}
$$

Where, $x_{i j}^{\prime}$ is the data after extreme deviation, $x_{i j}$ original data, $x_{i m a x}$ and $x_{i m i n}$ respectively the maximum and minimum data at the $i^{\text {th }}$ row. 
Table 3. Benchmark Values Corresponding to Integral Subgrade Safety Grade after Earthquakes.

\begin{tabular}{|c|c|c|c|c|c|c|}
\hline \multirow[b]{2}{*}{ Evaluation index } & \multirow[b]{2}{*}{ Code } & \multicolumn{5}{|c|}{ Safety grade } \\
\hline & & Safe & $\begin{array}{c}\text { Basically } \\
\text { safe }\end{array}$ & $\begin{array}{l}\text { Less } \\
\text { safe }\end{array}$ & Unsafe & Extremely unsafe \\
\hline Subgrade damage condition & $U_{1}$ & $\begin{array}{l}0-0.5 \\
1-0.88\end{array}$ & $\begin{array}{c}0.5-1 \\
0.88-0.75\end{array}$ & $\begin{array}{c}1-2 \\
0.75- \\
0.50\end{array}$ & $\begin{array}{c}2-3 \\
0.50- \\
0.25\end{array}$ & $\begin{array}{c}3-4 \\
0.25-0\end{array}$ \\
\hline $\begin{array}{c}\text { Topographical and } \\
\text { geomorphologic features } \\
\text { (original ground slope angle) }\end{array}$ & $U_{2}$ & $\begin{array}{l}0^{\circ}-10^{\circ} \\
1-0.83\end{array}$ & $\begin{array}{c}10^{\circ}-20^{\circ} \\
0.83-0.67\end{array}$ & $\begin{array}{c}20^{\circ}-30^{\circ} \\
0.67- \\
0.50\end{array}$ & $\begin{array}{c}30^{\circ}-45^{\circ} \\
0.50- \\
0.25\end{array}$ & $\begin{array}{c}45^{\circ}-60^{\circ} \\
0.25-0\end{array}$ \\
\hline $\begin{array}{l}\text { Aftershock magnitude (seismic } \\
\text { peak acceleration) }\end{array}$ & $U_{3}$ & $\begin{array}{c}0- \\
0.05 \mathrm{~g} \\
1-0.83\end{array}$ & $\begin{array}{c}0.05 \mathrm{~g}- \\
0.1 \mathrm{~g} \\
0.83-0.67\end{array}$ & $\begin{array}{l}0.1 \mathrm{~g}- \\
0.15 \mathrm{~g} \\
0.67- \\
0.50\end{array}$ & $\begin{array}{c}0.15 \mathrm{~g}- \\
0.2 \mathrm{~g} \\
0.50- \\
0.33\end{array}$ & $\begin{array}{c}0.2 \mathrm{~g}-0.3 \mathrm{~g} \\
0.33-0\end{array}$ \\
\hline Subgrade height (m) & $U_{4}$ & $\begin{array}{c}0-3 \\
1-0.91\end{array}$ & $\begin{array}{c}3-8 \\
0.91-0.77\end{array}$ & $\begin{array}{c}8-15 \\
0.77- \\
0.57\end{array}$ & $\begin{array}{c}15-25 \\
0.57- \\
0.29\end{array}$ & $\begin{array}{l}25-35 \\
0.29-0\end{array}$ \\
\hline Slope ratio & $U_{5}$ & $\begin{array}{l}1: 3-1: 2 \\
1-0.50\end{array}$ & $\begin{array}{l}1: 2-1: 1.75 \\
0.50-0.37\end{array}$ & $\begin{array}{c}1: 1.75- \\
1: 1.4 \\
0.37- \\
0.20\end{array}$ & $\begin{array}{l}1: 1.4- \\
1: 1.2 \\
0.20- \\
0.10\end{array}$ & $\begin{array}{l}1: 1.2-1: 1 \\
0.10-0\end{array}$ \\
\hline Daily rainfall intensity $(\mathrm{mm} / \mathrm{d})$ & $U_{6}$ & $\begin{array}{c}0-20 \\
1-0.90\end{array}$ & $\begin{array}{c}20-40 \\
0.90-0.80\end{array}$ & $\begin{array}{c}40-70 \\
0.80- \\
0.65\end{array}$ & $\begin{array}{l}70-100 \\
0.65- \\
0.50\end{array}$ & $\begin{array}{c}100-200 \\
0.50-0\end{array}$ \\
\hline
\end{tabular}

It should be noted that the indexes of aftershock magnitude, subgrade height, slope ratio and rainfall intensity are without maximum values. Taking aftershock magnitude for example, to normalize data, we have defined a range $(0 \mathrm{~g}, 0.3 \mathrm{~g})$. If the actual values of evaluation indexes exceed this range in the following calculations, it will be regarded as the sectional maximum value for calculations in the process of normalization. Moreover, original ground slope angles above $60^{\circ}$ are calculated as $60^{\circ}$.

(3) AHP determines weight

We compare relative importance of factors in pairs by 1 9 scaling procedure, select experienced experts to evaluate and score relative importance of each factor and establish determination matrix based on experts' opinions. See Table 4 for the results.

Table 4. Determination Matrix.

\begin{tabular}{ccccccc}
\hline & $\boldsymbol{U}_{\mathbf{1}}$ & $\boldsymbol{U}_{\mathbf{2}}$ & $\boldsymbol{U}_{\mathbf{3}}$ & $\boldsymbol{U}_{\mathbf{4}}$ & $\boldsymbol{U}_{\mathbf{5}}$ & $\boldsymbol{U}_{\mathbf{6}}$ \\
\hline$U_{1}$ & 1 & 5 & 4 & 7 & 7 & 5 \\
$U_{2}$ & $1 / 5$ & 1 & $1 / 2$ & 2 & 2 & 1 \\
$U_{3}$ & $1 / 4$ & 2 & 1 & 3 & 3 & 2 \\
$U_{4}$ & $1 / 7$ & $1 / 2$ & $1 / 3$ & 1 & 1 & $1 / 2$ \\
$U_{5}$ & $1 / 7$ & $1 / 2$ & $1 / 3$ & 1 & 1 & 1 \\
$U_{6}$ & $1 / 5$ & 1 & $1 / 2$ & 2 & 1 & 1 \\
\hline
\end{tabular}

In the Table, $U_{1}, U_{2}, U_{3}, U_{4}, U_{5}$ and $U_{6}$ are respectively subgrade damage condition, topographical and geomorphologic features, aftershock magnitude, subgrade height, slope ratio and rainfall intensity.

We employ AHP for consistency test to the above determination matrix, calculate the weight of each influencing factors and acquire consistency index $C R=0.0128<<0.1$, which passed consistency test. It can be seen that the determination matrix is reasonably structured and can be used to calculate weight.

The weights of each evaluation index factor are calculated as follows: 
Table 5. Weight Calculating Matrix.

\begin{tabular}{cccccccc}
\hline & $\boldsymbol{U}_{\mathbf{1}}$ & $\boldsymbol{U}_{\mathbf{2}}$ & $\boldsymbol{U}_{\mathbf{3}}$ & $\boldsymbol{U}_{\mathbf{4}}$ & $\boldsymbol{U}_{\mathbf{5}}$ & $\boldsymbol{U}_{\mathbf{6}}$ & $\boldsymbol{w}_{\boldsymbol{i}}$ \\
\hline \multirow{2}{*}{$U_{1}$} & 1.00 & 5.00 & 4.00 & 7.00 & 7.00 & 5.00 & 0.50 \\
& 00 & 00 & 00 & 00 & 00 & 00 & 25 \\
& 0.20 & 1.00 & 0.50 & 2.00 & 2.00 & 1.00 & 0.10 \\
$U_{2}$ & 00 & 00 & 00 & 00 & 00 & 00 & 47 \\
& 0.25 & 2.00 & 1.00 & 3.00 & 3.00 & 2.00 & 0.17 \\
$U_{3}$ & 00 & 00 & 00 & 00 & 00 & 00 & 59 \\
& 0.14 & 0.50 & 0.33 & 1.00 & 1.00 & 0.50 & 0.05 \\
$U_{4}$ & 29 & 00 & 33 & 00 & 00 & 00 & 83 \\
& 0.14 & 0.50 & 0.33 & 1.00 & 1.00 & 1.00 & 0.06 \\
$U_{5}$ & 29 & 00 & 33 & 00 & 00 & 00 & 54 \\
& 0.20 & 1.00 & 0.50 & 2.00 & 1.00 & 1.00 & 0.09 \\
$U_{6}$ & 00 & 00 & 00 & 00 & 00 & 00 & 32 \\
& & & & & &
\end{tabular}

We can see from Table 5 that the weights of each index are:

$$
W=\left(w_{1}, w_{2}, w_{3}, w_{4}, w_{5}, w_{6}\right)=
$$

$(0.5025,0.1047,0.1759,0.0583,0.0654,0.0932)$

\section{CASE STUDY}

As for the section K712+520 K712+640 from Guangyuan to Yaodu of Highway G212, the right side of the subgrade is excavation slope and the left side is high-filled embankment. The plane alignment is smooth and longitudinal gradient is gentle, which meet the requirement of Grade II highway in mountainous terrain. The road is paved with asphalt, with unfavorable evenness. The upper slope is not high, with the slope ratio 1:1. The lower slope is shoulder retaining wall slope, with the retaining wall $10 \mathrm{~m}$ high. The slope base is a natural hill, with slope ratio about 1:1.2.

Affected by earthquakes, the retaining wall at left collapsed, subgrade cracked and fell down, with width of $4 \mathrm{~m}$ and length of $34 \mathrm{~m}$. Subgrade filling is crushed stone. The remaining road pavement at left cracked densely, with seam width between $3 \mathrm{~cm} \sim 10 \mathrm{~cm}$, which brought potential danger of collapsing at any time and affected traffic greatly.

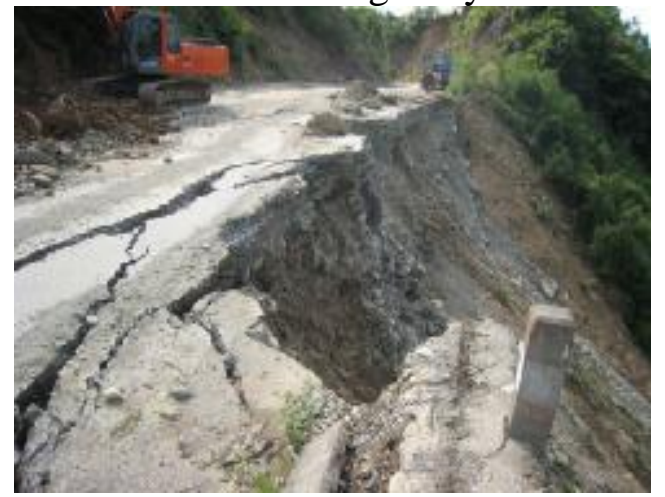

Fig. 1. Damage Condition of K712+530 K712+550. 
Table 6. Evaluation Index Values.

\begin{tabular}{ccccccc}
\hline $\begin{array}{c}\text { Evaluation } \\
\text { index }\end{array}$ & $\begin{array}{c}\text { Damage } \\
\text { condition }\end{array}$ & $\begin{array}{c}\text { Original } \\
\text { ground } \\
\text { slope } \\
\text { angle }\end{array}$ & $\begin{array}{c}\text { Aftershock } \\
\text { magnitude }\end{array}$ & Height & $\begin{array}{c}\text { Slope } \\
\text { ratio }\end{array}$ & $\begin{array}{c}\text { Rainfall } \\
\text { intensity }\end{array}$ \\
\cline { 2 - 7 } & $\boldsymbol{c}_{\mathbf{1}}$ & $\boldsymbol{c}_{\mathbf{2}}$ & $\boldsymbol{c}_{\mathbf{3}}$ & $\boldsymbol{c}_{\mathbf{4}}$ & $\boldsymbol{c}_{\mathbf{5}}$ & $\boldsymbol{c}_{\mathbf{6}}$ \\
\hline $\begin{array}{c}\text { Original } \\
\text { data }\end{array}$ & 2.85 & $40^{\circ}$ & $0.08 \mathrm{~g}$ & $10 \mathrm{~m}$ & $1: 1$ & $50 \mathrm{~mm}$ \\
Dimensionless & 0.29 & 0.42 & 0.73 & 0.71 & 0 & 0.75 \\
\hline
\end{tabular}

See Table 6 for the investigation results of all evaluation indexes of the section through survey. Subgrade damage condition evaluation is acquired by a fast evaluation method combining single weighted score and weighted average and its result has been normalized. To be clear, since subgrade shoulder wall collapsed at this section, the subgrade slope ratio is regarded as the most unsafe.

A fuzzy comprehensive evaluation relation matrix is established based on Table 6 as follows:

$$
R=\left[\begin{array}{l}
c_{1} \\
c_{2} \\
c_{3} \\
c_{4} \\
c_{5} \\
c_{6}
\end{array}\right]=\left[\begin{array}{ccccc}
0 & 0 & 0 & 0.65 & 0.35 \\
0 & 0 & 0 & 0.83 & 0.17 \\
0 & 0.9 & 0.1 & 0 & 0 \\
0 & 0.25 & 0.75 & 0 & 0 \\
0 & 0 & 0 & 0 & 1 \\
0 & 0.8 & 0.2 & 0 & 0
\end{array}\right]
$$

We obtain from fuzzy evaluation comprehensive principle that:

$$
\begin{gathered}
=(0.5025,0.1047,0.1759,0.0583,0.0654,0.0932) \\
\times\left[\begin{array}{ccccc}
0 & 0 & 0 & 0.65 & 0.35 \\
0 & 0 & 0 & 0.83 & 0.17 \\
0 & 0.9 & 0.1 & 0 & 0 \\
0 & 0.25 & 0.75 & 0 & 0 \\
0 & 0 & 0 & 0 & 1 \\
0 & 0.8 & 0.2 & 0 & 0
\end{array}\right] \\
=(0,0.2474,0.0800,1.2435,0.4291)
\end{gathered}
$$

We normalize the above results, so:

$$
\begin{gathered}
B=(0,0.1237,0.04,0.6218,0.2146) \\
b^{*}=\max \left\{v_{1}, v_{2}, \ldots, v_{5}\right\}=\{0,0.1237,0.04,0.6218,0.2146\}=v_{4}=0.6218
\end{gathered}
$$

We can know based on fuzzy comprehensive evaluation principle mentioned above that, as per calculation results, the section of subgrade belongs to the fourth evaluation set v4, namely unsafe condition. According to safety grade classifying standard described above, it is extremely dangerous for pedestrians and vehicles at this section and should prohibit other vehicles from passing through except for emergency vehicles. It can also establish a necessarily temporary access road. The road can only be resumed for normal operation after a large scale of repair and reinforcement to subgrade.

\section{CONCLUSIONS}

The determination results obtained by FACEM are basically consistent with the treatment advice proposed by experts after investigation and evaluation. However, we can get to know the membership degree of each evaluation unit to each evaluation through the evaluation results of FACEM. The results obtained by quantitative method contain more information and are more persuasive and more reliable. Furthermore, FACEM provides fixed evaluation steps and achieves evaluation by fuzzy mathematics. It is reasonable to deal with the uncertain information produced in the process of evaluation by such quantitative method. 


\section{ACKNOWLEDGEMENTS}

This work was financially supported by the Project of Chinese National Science Technology Ministry (2015BAK09B01), Chongqing Youth Talent of Science and Technology (cstc2014kjrcqnrc30004).

\section{REFERENCES}

[1] Xiao Shengxie, Wang Pingyi and Lv Enlin, Application of Fuzzy Mathematics in Civil and Hydraulic Engineering, Beijing, 2004, pp. 72-78.

[2] Jin Liqiang, Jin Meihai, "Optimization Design of Subgrade Slope Based on Fuzzy Theory", Shanxi Architecture, vol. 32, no. 17, pp. 27-34, 2006.

[3] Fu Bingxian, Tang Fei and Li Tianjiang, "Analysis of Subgrade's Long-term Stability by AHP and Fuzzy Mathematics Method", Geotechnical Engineering Technique, vol. 19, no. 6, pp. 48-53, 2005.

[4] Deng Zhihai, "Forecast Evaluation of Slope Stability of Pingshi-Zhangshi Section of Guangzhou-Lechang Highway", Research \& Application of Building Materials, vol. 36, no. 8, pp. 155-160, 2010.

[5] Zhang Jian, Wang Huoming and Wei Qiang, "Fuzzy Comprehensive Evaluation Method in Highway Slope Stability Analysis", Building Scientific Technology and Management, vol. 18, no. 6, pp. 6-7, 2010.

[6] Wu Wangping, Specifications for Design of Highway Subgrades (JTG D30-2004), Beijing, 2004, pp. 58-61.

[7] Xu Shubai, Analytic Hierarchy Process, Tianjin, 1988, pp. 267-269. 